\title{
Calcium Supplementation: A Review of Oral Calcium Intake on Human Health
}

\author{
Dr. Gurmeet Singh Sarla* \\ Department of General Surgery, Military Hospital Devlali, India
}

*Corresponding author: Dr. Gurmeet Singh Sarla, Senior Advisor Surgery, MH Devlali, Devlali, Nasik, Maharashtra, India

\begin{abstract}
Adequate calcium intake is essential for the maintenance of bone health and the preservation of bone mineral density. The lay person believes that calcium is always good for health. Successful marketing and various clinical practice guidelines have made prescribing calcium supplements a billion dollar market in recent years. The aim of this study was to scan the literature and find out whether calcium supplements should be prescribed to all patients with fractures so as to improve their bone healing or should it be restricted to elderly post- menopausal females who have osteoporotic bones. The inference drawn was that dietary calcium is easier to absorb and may have beneficial effects as compared to calcium supplements and it should be limited to the total daily intake to 1000-1200 mg optimally from dietary sources. Calcium supplementation does not significantly reduce fracture risk in postmenopausal women but it reduces the risk of osteoporosis. It increases the risk of urolithiasis. A favourable role of calcium has been seen in postmenopausal women, elderly population, children and adolescents. Calcium is a double-edged sword, which may be both potentially crucial and perilous and hence should be prescribed with caution.
\end{abstract}

Keywords: calcium; Osteoporosis; Dementia; Kidney stones; Constipation

\section{Introduction}

A frequently asked question by a healthy, young lady presenting with a limb fracture being managed conservatively with immobilisation in a plaster is "Should I take Calcium supplementation so that my fracture heals well?." Adequate calcium intake is essential for the maintenance of bone health during growing phases [1] and the preservation of bone mineral density in elderly individuals [2]. Calcium supplementation is a widespread practice in different age-groups and has been promoted widely to improve bone density [3]. The lay person believes that calcium is always good for health due to successful marketing and various clinical practice guidelines and prescribing calcium supplements has become a billion dollar market in recent years and has been taken by millions of both men and women, children, adults, and the elderly wishing to improve their skeletal health.

\section{Aim}

The aim of this review article was to find out whether calcium supplements should be prescribed to all patients with fractures so as to improve their bone healing or should it be restricted to elderly post- menopausal females who have osteoporotic bones.

\section{Discussion}

A. Introduction: Osteoporosis is one of the leading causes of disability in the elderly. Because calcium deficiency contributes to osteoporosis, daily dietary calcium intake of $1,000-1,200 \mathrm{mg}$ is recommended [4]. Such a large calcium intake through diet alone can be difficult; therefore, calcium supplements are widely used [4]. Epidemiological studies have demonstrated that a significant number of population throughout the globe fail to achieve the recommended daily calcium intake [5]. In addition to its pivotal role in bone metabolism, the potential role of calcium in non-skeletal tissues has also been investigated, particularly in elderly people [6].

B. Role of Calcium: Calcium is an important and integrative component of human body with $99 \%$ of the body's calcium being contained within the skeleton [7]. Calcium homeostasis plays a major role in maintaining human life activities, such as maintenance of the skeleton, regulation of hormonal secretion, transmission of nerve impulses, and vascular activities [8]. The homeostasis of calcium is mainly maintained by both parathyroid hormone (PTH) and calcitonin [9]. 


\section{Benefits of Calcium Supplementation}

A. Osteoporosis: Osteoporosis is a skeletal disorder associated with aging and characterized by compromised bone strength due to reduced bone mass and reduced bone quality leading to increased bone fragility thereby predisposing a person to increased risk of fracture, notably at the vertebrae, hip, and forearm. It is suggested that Vitamin D and calcium supplementation, either in the form of calcium supplements or dietary calcium, plays a positive role in prevention od osteoporosis in people of different ages and genders. Calcium supplementation plays a protective role for bone health, improving bone mass density (BMD) and decreasing morbidity of osteoporosis and osteoporotic fractures in different genders and age-groups [10].

B. Postmenopausal women: Bone remodelling is accelerated in the peri-menopausal and postmenopausal periods and is characterized by a decrease in estrogen production and an increase in resorption of calcium from bone resulting in a marked decrease in bone density. Calcium supplementation may be recommended in postmenopausal women with a history of osteoporotic fractures, a diagnosis of osteoporosis, vitamin D deficiency, or a high risk for osteoporosis (eg, primary ovarian insufficiency) [11] but are not of any proven benefit in primary prevention of fractures in community dwelling asymptomatic premenopausal women [12].

C. Pregnant and lactating women: Calcium supplementation in pregnant or lactating women for the skeletal health of foetus and mother is of doubtful benefit. In a study in pregnant women in Gambia, West Africa, with low calcium intakes, calcium supplement resulted in significantly lower bone mineral content, bone area, and BMD at the hip throughout 12-month lactation. The women also had greater decreases in bone mineral during lactation at the lumbar spine and distal radius and had biochemical changes consistent with greater bone mineral mobilization [13]. In pregnant and lactating women with low calcium intakes, calcium supplementation is recommended [14].

D. Children: For growing children, bone modeling (i.e., formation over resorption) is the predominant skeletal process which requires mineralization; hence, calcium requirements are increased, particularly during neonatal and pubertal growth spurts. For healthy children, there has been no recommendation for routine calcium supplementation, however children with a high risk of osteoporosis (eg, celiac disease, inflammatory bowel disease, or congenital bone disorder) or low calcium intake may benefit from calcium supplementation. In a study conducted in rural Gambian children accustomed to a low-calcium diet, calcium supplementation resulted in higher bone mineral content and BMD [15].

E. Cardiovascular System: A study conducted among an elderly Chinese population indicated that dietary calcium intake could reduce the risk of death from all causes and cardiovascular diseases [16]. Another study conducted among postmenopausal women revealed that high intake of dietary and supplemental calcium were associated with a decrease in the mortality of ischemic heart disease [17].

F. Gastrointestinal tract: A randomized, double-blind trial performed on people with a history of colorectal adenomas, receiving either $1,200 \mathrm{mg} / \mathrm{d}$ elemental calcium or placebo has revealed a significant reduction in the risk of recurrent colorectal adenomas with calcium supplementation6. Calcium carbonate is more often associated with gastrointestinal side effects, including constipation, flatulence, and bloating [18]. The explanation behind those findings is the ability of calcium to combine with bile acids in the intestines, reducing the rectal epithelial proliferation rate [19].

\section{Adverse effects of Calcium Supplementation}

A. Cardiovascular System: It is estimated by a metaanalysis (including eleven randomized controlled trials) that calcium supplements have up to $30 \%$ increase risk for myocardial infarction [20]. The explanation behind these findings is that calcium supplements potentially contribute to elevated serum calcium levels and possibly accelerated cardiovascular calcification [21].

B. Gastrointestinal Diseases: Calcium supplements may increase the incidence of constipation, severe diarrhoea, and abdominal pain [22].

C. Renal Stones: A major concern regarding the safety of calcium has been the occurrence of kidney stones. An abnormality of urinary super-saturation is one of the main factors for the formation of kidney stones23. Individuals who consumed any amount of supplemental calcium had an increased risk for kidney stones compared with individuals who did not consume supplemental calcium [24].

D. Age Related Macular Degeneration: A recent crosssectional study found that $>800 \mathrm{mg} / \mathrm{d}$ of calcium consumption in people aged $>67$ years may increase the risk of age related macular degeneration compared with those who do not take calcium [25].

E. Dementia and Alzheimer's Disease: Some trials have reported an association between calcium supplementation and increased risk for vascular events [26]. Vascular risk factors are related to vascular dementia and Alzheimer disease [27]. Calcium supplementation might have direct toxic effects on vulnerable neurons, because the increased calcium levels may amplify ischemic cell death and worsen the outcome after cerebrovascular events [19]. calcium influx and intracellular calcium overload have a crucial role in apoptosis and necrosis [28]. The mechanism of calcium supplements in the pathogenesis of dementia could be the steep increase in serum calcium levels caused by the supplements [20]. Calcium plays a central role in the mechanisms of cell death. 
In necrosis, the transmembrane influx of calcium ions activates proteases that are responsible for degrading critical proteins and disrupting membrane function [29].

F. Dietary Calcium: Dairy products in the form of milk, yogurt, and cheese are rich sources of calcium. About 72 percent of calcium comes from milk, cheese and yogurt and from foods to which dairy products have been added as in pizza, lasagna, dairy desserts. The remaining calcium comes from vegetables ( 7 percent); grains (5 percent); legumes (4 percent); fruit (3 percent); meat, poultry, and fish ( 3 percent); eggs ( 2 percent); and miscellaneous foods ( 3 percent) [30].

\section{G. Difference between Dietary Calcium and} Supplementary Calcium: The difference between dietary calcium and calcium intake by supplements could be explained by variations in corresponding changes in serum calcium concentration. Dietary intake does not increase the serum calcium levels to the same extent as supplements20. In addition, dietary calcium intake involves simultaneous intake of all other components of calciumcontaining foods and much lower dosages of calcium than calcium supplements.

\section{Conclusion}

Dietary calcium is easier to absorb and may have beneficial effects as compared to calcium supplements. Calcium from food sources has not been linked to morbidity, so limiting dietary consumption would not be advised. The recommendation should be to limit the total daily intake to $1000-1200 \mathrm{mg}$, optimally from dietary sources. Different dosages of calcium may induce different results. A favourable role of calcium has been seen in postmenopausal women, elderly population, children and adolescents. Calcium prevents osteoporosis but at the same time, increases the occurrence of cardiovascular diseases and risk of urolithiasis. Calcium supplementation does not significantly reduce fracture risk in postmenopausal women but it reduces the risk of osteoporosis. Calcium is a double-edged sword, which may be both potentially crucial and perilous and hence should be prescribed with caution. The issue of safety in people receiving calcium has long been a matter of debate. There is an abundance of data for beneficial effects and side effects in the literature on the role of calcium. All taken together, it is important to balance the advantages and disadvantages of calcium supplementation on human health [31].

\section{References}

1. Krall EA, Dawson-Hughes B (1993) Heritable and life-style determinants of bone mineral density. J Bone Miner Res 8(1): 1-9.

2. National Institutes of Health (U.S.) (1994) Optimal calcium intake. Bethesda: National Institutes of Health. pp. 1-31.

3. Reid IR (2014) Should we prescribe calcium supplements for osteoporosis prevention? J Bone Metab 21(1): 21-28.
4. Bauer DC (2013) Clinical practice: calcium supplements and fracture prevention. N Engl J Med 369(16): 1537-1543.

5. Cashman KD (2002) Calcium intake, calcium bioavailability and bone health. Br J Nutr 87(Suppl 2): S169-S177.

6. Baron JA, Beach M, Mandel JS, van Stolk RU, Haile RW, et al. (1999) Greenberg ER Calcium Polyp Prevention Study Group. Calcium supplements for the prevention of colorectal adenomas. N Engl J Med 340: 101-107.

7. Emkey RD, Emkey GR (2012) Calcium metabolism and correcting calcium deficiencies. Endocrinol Metab Clin North Am 41(3): 527-556.

8. Krebs J, Agellon LB, Michalak M (2015) Ca (2+) homeostasis and endoplasmic reticulum (ER) stress: An integrated view of calcium signaling. Biochem Biophys Res Commun 460(1): 114-121.

9. Kleeman CR, Massry SG, Coburn JW (1971) The clinical physiology of calcium homeostasis, parathyroid hormone, and calcitonin. I. Calif Med 114(3): 16-43.

10. Straub DA (2007) Calcium supplementation in clinical practice: a review of forms, doses, and indications. Nutr Clin Pract 22(3): 286-296.

11. Islam MZ, Shamim AA, Viljakainen HT (2010) Effect of vitamin D, calcium and multiple micronutrient supplementation on vitamin $\mathrm{D}$ and bone status in Bangladeshi premenopausal garment factory workers with hypovitaminosis D: a double-blinded, randomised, placebo-controlled 1-year intervention. Br J Nutr 104(2): 241-247.

12. US Preventive Services Task Force. Grossman DC, Curry SJ, et al. (2018) Vitamin D, Calcium, or Combined Supplementation for the Primary Prevention of Fractures in Community-Dwelling Adults: US Preventive Services Task Force Recommendation Statement. JAMA 319(15): 15921599.

13. Jarjou LM, Laskey MA, Sawo Y, Goldberg GR, Cole TJ (2010) Effect of calcium supplementation in pregnancy on maternal bone outcomes in women with a low calcium intake. Am J Clin Nutr 92(2): 450-457.

14. Thomas M, Weisman SM (2006) Calcium supplementation during pregnancy and lactation: effects on the mother and the fetus. Am J Obstet Gynecol 194(4): 937-945.

15. Dibba B, Prentice A, Ceesay M, Stirling DM, Cole TJ, et al. (2000) Effect of calcium supplementation on bone mineral accretion in gambian children accustomed to a low-calcium diet. Am J Clin Nutr 71(2): 544-549.

16. Chan R, Leung J, Woo J (2013) A prospective cohort study examining the associations of dietary calcium intake with all-cause and cardiovascular mortality in older Chinese community-dwelling people. PLoS One 8(11): e80895.

17. Bostick RM, Kushi LH, Wu Y, Meyer KA, Sellers TA, et al. (1999) Relation of calcium, vitamin D, and dairy food intake to ischemic heart disease mortality among postmenopausal women. Am J Epidemiol. 149(2): 151161.

18. Straub DA (2007) Calcium supplementation in clinical practice: a review of forms, doses, and indications. Nutr Clin Pract 22(3): 286-296.

19. Welberg JWM, Kleibeuker JH, Dermeer RV, Mulder NH, de Vries EGE, et al. (1991) Calcium and the Prevention of Colon Cancer. Scand J Gastroenterol 26(Sup 188): 52-59.

20. Bolland MJ, Avenell A, Baron JA (2010) Effect of calcium supplements on risk of myocardial infarction and cardiovascular events: meta-analysis 341: c3691.

21. West SL, Swan VJ, Jamal SA (2010) Effects of calcium on cardiovascular events in patients with kidney disease and in a healthy population. Clin J Am Soc Nephrol 5(Suppl 1): S41-S47.

22. Lewis JR, Zhu K, Prince RL (2012) Adverse events from calcium supplementation: relationship to errors in myocardial infarction selfreporting in randomized controlled trials of calcium supplementation. J Bone Miner Res 27(3): 719-722. 
23. Worcester EM, Coe FL (2010) Clinical practice Calcium kidney stones. N Engl J Med 363(10): 954-963.

24. Curhan GC, Willett WC, Speizer FE, Spiegelman D, Stampfer MJ (1997) Comparison of dietary calcium with supplemental calcium and other nutrients as factors affecting the risk for kidney stones in women. Ann Intern Med 126(7): 497-504.

25. Kakigi CL, Singh K, Wang SY, Enanoria WT, Lin SC (2015) Self-reported Calcium Supplementation and Age-Related Macular Degeneration. JAMA Ophthalmol 133(7): 746-754.

26. Bolland MJ, Grey A, Avenell A, Gamble GD, Reid IR (2011) Calcium supplements with or without vitamin D and risk of cardiovascular events: reanalysis of the Women's Health Initiative limited access dataset and meta-analysis 342: d2040.
27. Kloppenborg RP, van den Berg E, Kappelle LJ, Biessels GJ (2008) Diabetes and other vascular risk factors for dementia: which factor matters most? A systematic review. Eur J Pharmacol 585(1): 97-108.

28. Chung JW, Ryu WS, Kim BJ, Yoon BW (2015) Elevated calcium after acute ischemic stroke: association with a poor short-term outcome and longterm mortality. J Stroke 17(1): 54-59.

29. Zhivotovsky B, Orrenius S (2010) Cell cycle and cell death in disease: past, present and future. J Intern Med 268(5): 395-409.

30. Hotchkiss RS, Strasser A, McDunn JE, Swanson PE (2009) Cell death. N Engl J Med 361(16):1570-1583.

31. Aaron JE, Gallagher JC, Anderson J, Stasiak L, Longton EB, et al. (1974) Frequency of osteomalacia and osteoporosis in fractures of the proximal femur. Lancet 1(7851):229-233.

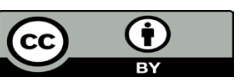

This work is licensed under Creative Commons Attribution 4.0 License

To Submit Your Article Click Here: Submit Article

DOI: $10.32474 /$ OAJOM.2019.03.000151

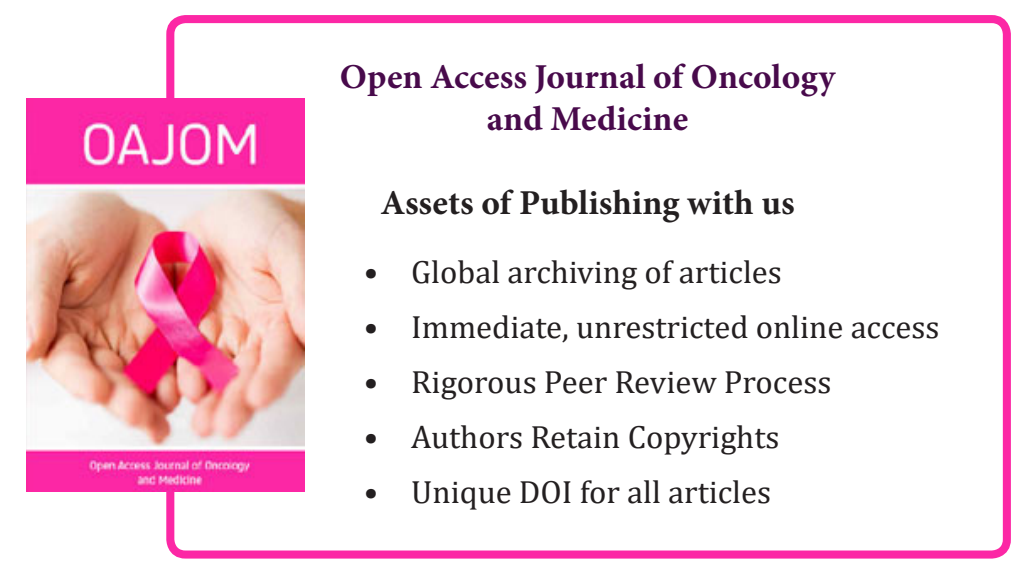

